\title{
CORRECTION
}

View Article Online

View Journal I View Issue

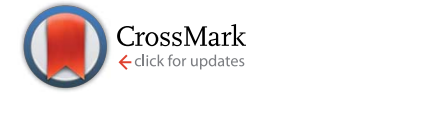

Cite this: Nat. Prod. Rep., 2017, 34, 329

DOI: $10.1039 / c 7 n p 90008 b$

www.rsc.org/npr

\section{Correction: Fluorescent natural products as probes and tracers in biology}

Romain Duval ${ }^{\star a}$ and Christophe Duplais ${ }^{b}$

Correction for 'Fluorescent natural products as probes and tracers in biology' by Romain Duval et al., Nat. Prod. Rep., 2017, DOI: 10.1039/c6np00111d.

The authors regret that the structure of the synthetic analogue shown in Fig. 27 of the original article was incorrect. The revised structure is shown below.

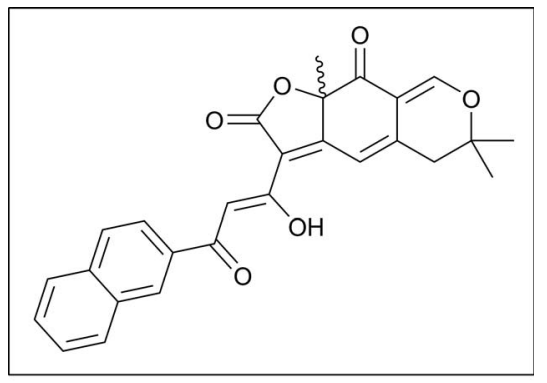

Synthetic analogue

The Royal Society of Chemistry apologises for these errors and any consequent inconvenience to authors and readers.

IRD, UMR 216 IRD MERIT (Mère et Enfant face aux Infections Tropicales), Université Paris-Descartes, 4 Avenue de l'Observatoire, 75006 Paris, France. E-mail: romain.duval@ ird.fr; Fax: +33-1-5373-9617; Tel: +33-1-5373-9933

${ }^{b}$ CNRS, UMR 8172 EcoFoG (Ecologie des Forêts de Guyane), AgroParisTech, Cirad, INRA, Université des Antilles, Université de Guyane, 23 avenue Pasteur, 97300 Cayenne, France. E-mail: christophe.duplais@ecofog.gf; Tel: +594-694-236-921 